\title{
NARRATIVAS DO ÍNDico NA ESCRITA DE JPBC - UMA GEOGRAFIA TRANSNACIONAL
}

\begin{abstract}
Ana Mafalda Leite ${ }^{1}$
Resumo: O artigo trata da importância das narrativas do Oceano Índico, representadas diferentemente na escrita de João Paulo Borges Coelho, pela descrição do historiador e e recriadas imaginariamente pelo escritor, enquanto elementos configuradores da área de estudos do Oceano Índico ou Indian Ocean Studies. A narrativa é um elemento de trânsito cultural, recriadora de uma geografia do espaço índico, e da História e estórias que nele circulam.

Palavras-chave: Estudos sobre o Oceano Índico; narrativa; geografia.

We prefer to treat the Indian Ocean region as one, among many, liminal spaces of hybrid evolution, an area whose boundaries are both moveable and porous, which brings us close to Devleena Ghosh and Stephen Muecke's notion of transnational imaginative geography. (MOORTY; JAMAL, 2010, p. 5) ${ }^{2}$

Neste artigo pretendemos refletir sobre a importância da narrativa, enquanto elemento cultural de trânsito, que enlaça as margens do Oceano Índico, criando uma geografia do espaço entre costa litorânea e ilhas, e demonstrar como nos textos de João Paulo Borges Coelho (JPBC) se arquiteta esse trânsito e se entrelaçam também dois diferentes tipos de narrativa de representação da topografia do Oceano Índico: a meta-
\end{abstract}

1 Professora Associada com Agregação, FLUL/CESA, Universidade de Lisboa, Portugal: anamafaldaleite@gmail.com.

2 "Preferimos tratar a região do Oceano Índico como um, de entre muitos, espaços liminares de evolução híbrida, uma área cujas fronteiras são móveis e porosas, o que nos aproxima da noção de geografia imaginativa transnacional de Devleena Ghosh e Stephen Muecke.” Todas as traduções de citações são nossas. 
narrativa descritiva de origem histórica e a literária-ficcional, que se configura na conjunção do mito com a história. É nessa duplicidade criativa do autor moçambicano que se mapeia uma fragmentária geografia índica, que se constrói em diferentes narrativas.

The Indian Ocean is a kind of Foucauldian heterotopia, a space of diverse, fragmentary and alternate narratives which empirically resist any normalizing gaze. (GOSH; MUECKE, 2007, p. 5) ${ }^{3}$

\section{PRIMEIRA NARRATIVA, A HISTÓRIA}

The issue of spatial boundaries helps us theorize and place in historical context the Indian Ocean as an inter-regional arena of political, economic, and cultural interaction. (BOSE, 2006, p. 6) ${ }^{4}$

Em texto ensaístico apresentado em Barcelona em 2009, "O Índico como lugar" (COELHO, 2009), 5 JPBC reflete sobre o Índico enquanto historiador e escritor procurando desvendar, por meio de noções como as de spiritu loci ou genius loci, o lugar enquanto entidade autónoma, com vida própria.

A proposta do autor na sua intervenção consistiu em partir do princípio de que os lugares são guardados por Genii e que existem itinerários da imaginação que nos transportam dos simples lugares até aos lugares literários; partindo dessa argumentação, ensaia a aplicação do mesmo princípio ao Oceano Índico.

aqui falamos de um espaço amplo que, sendo embora o mais pequeno dos três grandes oceanos - um terço do Pacífico, menos 10 por cento que o Atlântico - ocupa uma vasta área de quase setenta milhões de quilómetros quadrados. Ainda por cima uma área líquida (e haverá entidade mais incapturável do que as águas?). Mais do que isso, um espaço com muitas facetas que são outras tantas tonalidades que lhe são conferidas pelas margens. E margens, neste caso, muito diversas. Como depreender daqui uma unidade que nos permita, a partir dela, chegar ao "Genius"? (COELHO, 2009, p. 5)

\footnotetext{
3 "O Oceano Índico é uma espécie de heterotopia foucauldiana, um espaço de narrativas alternativas, diversas e fragmentárias, que resistem empiricamente a qualquer olhar normativo."

4 "A questão das fronteiras espaciais ajuda-nos a teorizar e a situar no contexto histórico o Oceano Î́ndico como uma arena inter-regional de interação política, econômica e cultural.” 5 Cópia do texto cedida pelo autor.
} 
JPBC pensa a literatura não como a definição de uma rota planeada que é preciso percorrer, mas antes como um campo de experimentações, de acordo com suas próprias palavras. Faz parte da sua arte narrativa nomear lugares que estão prisioneiros das sombras. Sua formação como historiador e sua experiência de viajante da literatura e do Índico permitem-lhe perceber a alma desse mar e seguir as palavras de um outro historiador, Michael Pearson (2003, p. 5), quando este afirma:

Rather than look out at the oceans from the land, as so many earlier books have done, a history of an ocean has to reverse this angle and look from the sea to the land, and most obviously to the coast. There has to be attention to land areas bordering the ocean, that is the littoral. ${ }^{6}$

Segundo Coelho (2009, p. 5),

Foi deixando-se cruzar em viagens de longo curso que o Índico revelou as suas margens distantes como margens, não mais pequenos mundos fechados. Desde logo o Índico das frotas chinesas de barcos bojudos e deselegantes, verdadeiros paquidermes navegantes que em 1421, oriundos de Calecute, escalaram Mogadiscio, Zanzibar e Sofala num empreendimento que envolveu árabes, venezianos e hindus [...].

Retrocedendo no tempo, o escritor desvela um Índico ainda mais antigo, de antes do século IX, sulcado por frotas de dhows árabes, persas e hindus, seguindo o ritmo da monção. E refere a importância dos trânsitos de pesca costeiros e comerciais, enumerando as diversas tipologias de embarcações que se encontram na longa costa índica de Moçambique:

Destes pequenos barcos da costa moçambicana inventariei lanchas e almadias de diversos tipos um pouco por todo o lado, chatas, uombes, pangaias e chitatarros na baía de Maputo, caíques e hafas na Ilha de Moçambique, mutereres e cangaias nas Chocas, machuas, mádias, inchós, dhows e mitumbuís em Pemba, cangaias e mutereres em Relanzapo, cumpulos na baía de Memba, caláuas, ashuis, galavas e pangaias em Nova Sofala. (COELHO, 2009, p. 5)

O autor demonstra que, mais que qualquer outro oceano, o Índico é propício à navegação à vela. Uma das características distintivas desse oceano, tal como nos explica, são os ventos de monção, que sopram a norte do Equador - metade do ano a monção de nordeste, e, na outra metade, a de sudoeste - criando um mecanismo altamente favorável às ligações

6 “[...] quando afirma que a visão sobre o oceano deve ser reconfigurada, dando preferência ao olhar que se orienta do mar para a terra, em especial para a costa e para as zonas de terra litorâneas." 
entre o subcontinente indiano, a península arábica e a costa africana. Criativa é a forma como, através da explicação da etimologia da palavra monção, JPBC nos vai lentamente demonstrando as ligações secretas e entrelaçadas do Genius desse mar.

\begin{abstract}
Segundo uns dicionários, a palavra monção deriva do italiano monsore e esta do malaio musim, significando "época do ano"; segundo outros, a palavra inglesa monsoon deriva do holandês monsooen, esta do português monção, que por sua vez derivaria do árabe mausim, com o mesmo significado. De qualquer forma, tais derivações mostram eloquentemente, por via da etimologia (da história das palavras e das ligações secretas que estas estabelecem entre si) como o acto de navegar ligava todas estas margens. (COELHO, 2009, p. 6)
\end{abstract}

A navegação de longo curso vai permitir os contactos entre diferentes margens, aproximando africanos, árabes, chineses, indonésios, indianos, persas e, mais tarde, europeus. Por outro lado, permitiu instaurar trocas materiais de todo tipo, de tecidos, de flora, de fauna, bem como permeabilizar a chegada de novas religiões e alfabetos. As zonas litorâneas partilham características próprias e muito antigas cumplicidades culturais. São exemplos disso a difusão do islamismo ou o surgimento da cultura e da língua swahili, que se alastraram por toda a costa desde o sul da Somália até ao norte de Moçambique.

Na sequência da argumentação e do levantamento de algumas das características que singularizam o Índico, como lugar histórico e cultural, o autor estabelece as referências da paisagem e os sinais que permitem estabelecer a individualidade do mar Îndico:

Por esta altura penso estar já estabelecida uma certa individualidade deste grande oceano: na periferia feita de praias amarelas e objectos aguçados (os coqueiros, os minaretes das mesquitas, os velhos padrões portugueses e as pequenas velas triangulares), nos seus ventos constantes e tão característicos, nos seus amuos destruidores. Em características físicas que suscitam a imaginação. (COELHO, 2009, p. 8)

Neste sentido o historiador eescritorJPBC sintoniza-se comas palavras dos estudiosos Shanti Moorty e Ashraf Jamal (2010, p. 4) quando estes afirmam "We propose that the Indian Ocean region possesses an internal commonality which enables us to view it as an area in itself: commonalities of history, geography, merchant capital and trade, ethnicity, culture, and 
religion".7 Por outras palavras, o historiador moçambicano, ao caracterizar alguns dos aspectos do genius loci das regiões costeiras do Oceano Índico, enquadra-se teórica e criativamente na discussão dos Ocean Studies:

So what exactly does Indian Ocean studies entail? Our focus is the Indian Ocean region, by which we mean the ocean itself, its littoral and hinter-land, fully embedded in the global, and viewed from the perspective of contemporary human interests, human histories, human movements. (MOORTY; JAMAL, 2010, p. 5$)^{8}$

\section{SEGUNDA NARRATIVA, O MITO E A PARÁBOLA}

Histórias humanas e humanos movimentos são, afinal, o que o autor moçambicano desvela nas suas narrativas sobre o Índico. Nos dois livros de contos de JPBC, intitulados conjuntamente Índicos indícios, constatamos no título que o jogo de palavras e a aliteração poética apontam para o trânsito e para a consonância dos sinais deste genius loci índico em toda a costa moçambicana. Faremos aqui referência em especial a duas narrativas, "Ibo Azul" (Setentrião, 2005, ovolume) e "A força do mar de Agosto" (Meridião, 2005, 2o volume), para representarem a narrativa literária do autor sobre o Î́ndico.

Aliás, no final da sua comunicação de 2009, o autor refere já um dos contos, o segundo que analisaremos neste artigo, bem como o seu conhecimento e gosto pelas viagens, realizadas pela costa do Índico: "Há escassos três meses voltei a percorrer 2000 quilómetros de costa, a partir da margem apalpando o mar como quem apalpa o lombo de um bicho, a ver se lhe descubro o segredo. Estou certo de que um dia conseguirei" (COELHO, 2009, p. 11). E resgata um comentário sobre o conto "A força do mar de Agosto" nos seguintes termos:

Dedico-me portanto a fazer inventários, e desses inventários faz parte a listagem dos despojos que o Genius do Índico guarda na sua caverna. Recorrendo ao artifício de tornar o mar transparente pude descobrir, no chão da baía de Maputo, entre mil outras coisas, um galeão austríaco do século XVIII cheio

7 "Consideramos que a região do Oceano Índico possui uma rede de afinidades internas que nos permite vê-la como uma área em si, de partilha da história, da geografia, do capital mercantil, do comércio, de etnias, de culturas e de religiões."

8 "A que se dedicam então os estudos do Oceano Índico? O nosso foco é a região do Oceano Î́ndico, que consideramos ser o próprio oceano, o litoral e interior, globalmente enquadrados e percecionados de acordo com as histórias, os movimentos e os interesses humanos contemporâneos." 
de panos e colheres de prata, do acto de comércio que ficou por consumar ficando os africanos a comer à mão e os europeus sem os almejados pentes de marfim, despenteados; um pequeno avião afundado com os dois pilotos lá dentro, ostentando gestos suspensos que faziam parte de uma amaragem de emergência; um rebocador na barra misteriosamente desaparecido; e, claro, milhares de pequenos pescadores afogados, serenamente adormecidos nas planícies e jardins do fundo do mar, as canoas feitas féretros, as redes mortalhas.

(COELHO, 2009, p. 11)

As narrativas do autor moçambicano retomam, com esses dois livros de contos, as margens costeiras do país e suas diferencialidades transnacionais culturais índicas, por contraste com os lugares do interior. Escreve JPBC:

África é um continente de interiores, é lá que se situavam as grandes unidades políticas pré-coloniais, os chamados impérios, enquanto o litoral se esfarelava em pequeníssimas unidades de soberania disputada. Há portanto este contraste entre as culturas hierárquicas do ferro, das armas e dos tambores, e as pequenas culturas comerciais, das velas de pano e das redes de pesca. Falei já na minuciosa pequena arte da navegação costeira e pesqueira africana, a arte dos troncos de árvore escavados e das redes pacientemente entretecidas.

(COELHO, 2009, p. 5)

A relação entre tempo e espaço na escrita das narrativas de Índicos indícios desempenha um papel fundamental na reflexão sobre memórias ocultas e sobre o esquecimento histórico, sobre o palimpsesto dos trânsitos comerciais e coloniais, que tiveram lugar muitos séculos antes. $\mathrm{O}$ Oceano Índico representado nos contos - que se localizam em diferentes ilhas, como Ibo, Santa Carolina, Ilha de Moçambique, Xefina, baías e cidades portuárias - apresenta-se como um reservatório secreto de uma memória simultaneamente cultural e histórica. Assim o demonstram as duas narrativas escolhidas para este artigo, "Ibo azul" e "A força do mar de Agosto", que apresentam o Índico como lugar de criação do mundo e topografia da memória.

A primeira narrativa transforma a noção de tempo em momento sacral, ao passo que a segunda faz uso crítico e moral da parábola para refletir sobre um oceano transformado em terra ou em deserto, mostrando que o mar, afinal, é também outro tipo de terra e de habitação.

No primeiro conto, relata-se o percurso de um homem que inicia sua jornada a partir do bairro do cemitério do Ibo, Munaua, e evoca memórias do século dezanove, através dos nomes das lápides, que porventura 
reconhece, ou imagina, lembrando e descrevendo o espaço/tempo numa sincronicidade quase absoluta.

Essa conjunção sacral do tempo com o espaço faz com que a narrativa assuma todas as características de um mito inaugural. Com efeito, quando o personagem se deslocar do cemitério para a baía, há como que um início de mundo, quando se faz o relato do encontro de um homem, estrangeiro, que percorre a ilha, com uma mulher nativa, com máscara de m'siro (máscara de beleza feita com um pó branco, de origem árabe), que apanha na praia ameijoas.

Num certo tempo veio vindo um homem. Caminhava depressa, como se o chamasse um encontro desde há muito aprazado. E só o facto de se deter a espaços, olhando curioso as minúsculas criaturas do chão da praia, permitia adivinhar que afinal era apenas a ansiedade que o empurrava, apenas a impaciência de permanecer no mesmo lugar. (COELHO, 2005, p. 192)

Esse encontro principial pode ter tido lugar no passado ou no presente - "Num certo tempo" - quase encenando o narrador a arte de "era uma vez", levando o leitor a tomar consciência da intemporalidade da estória, em que a lentidão e beleza femininas contrastam com a pressa e urgência masculinas. Tal como as casas, as árvores, o mar, a mulher que emerge da praia é uma quase visão, que confere à paisagem a erótica dimensão humana, o desejo capaz de anular a distância.

\footnotetext{
Por um momento, enquanto do outro lado o homem prossegue a caminhada, a mulher fica assim, o tronco direito, as mãos entreabrindo o pano que lhe cobre o ventre tenro para renovar o nó que o fecha sobre os seios fartos. Lentamente os dedos precisos agarram as pontas, manipulam-nas, e o nó já largo e lasso volta a ser fino e apertado. É muito jovem esta mulher, mas o homem notará antiquíssimos sinais nesse olhar que ela espalha, quando o puder ver. Quando entre os dois já não houver a distância que ainda falta percorrer. (COELHO, 2005, p. 195)
}

O narrador faz desse encontro uma espécie de momento auge de criação, entre quem chega de fora e quem está fincado na terra: "Pouco falta para que se encontrem, uma vez que convergem para o mesmo lugar" (COELHO, 2005, p. 197). Por outro lado, a mulher, ao representar simbolicamente a terra, e o homem, o mar, evocam um movimento de ondulação entre quem chega, o barco, quem recebe, a terra, em que o trânsito fora/dentro e mar/terra configuram a litorânea condição índica de partilha cultural: 
Para ter lugar o encontro que está para acontecer não basta que cada um dos dois caminhe na direcção certa. É também necessária a espera. De outro modo seria como quase sempre acontece, o espaço e o tempo desentendendo-se, multiplicando-se os atrasos, fortalecendo-se as amargas solidões. (COELHO, 2005, p. 202)

Esperam a espera que se espera numa ilha, de ver os barcos a chegar, quando irão partir, mais a espera particular deste lugar onde o tempo adormeceu. (p. 203)

Lembremo-nos, porém que o conhecimento do homem é universal, enquanto que a mulher se apoia somente nas histórias das avós e naquilo que as margens do Índico deixam ver. (p. 205)

Nem o homem, nem a mulher, têm nome, enquanto que os antepassados do lugar são nomeados por seus nomes próprios. Esses dois seres formam um par da criação, representando simbolicamente o movimento do mar entre partir e chegar, o cruzamento de diferentes identidades. O olhar da mulher é descrito como misterioso e insondável e a máscara de m'siro, que lhe cobre o rosto, impede a revelação e atrai o desejo do homem. Esse homem e essa mulher representam duas faces do mundo, "estabelecendo preciosa ponte entre duas margens que fosse vital unir" (COELHO, 2005, p. 209) e que o Oceano uniu em seu movimento. "Ocorreu-lhe até, sem saber já em que momento, que estivessem os dois mergulhados, e a praia inteira, nas águas aniladas e invertidas de um espelho." (p. 210).

Nessa narrativa se faz ainda a descrição e enumeração dos diferentes tipos de embarcação empregues para as tarefas pesqueiras e de navegação; a vida dos habitantes da ilha faz-se na fronteira do mar com a terra, e os diversos barcos metaforizam uma outra forma de estar em terra, uma relação mais próxima com o oceano:

Os barcos chegam e partem para Tandanhangue e outros lugares, ou adejam em redor da ilha. Grandes kavokos de madeira grossa puxados pelo remar cadenciado e vigoroso dos marinheiros; kalawas com seus negros panos como se cumprissem um pressagio luto, barbatanas de tubarão sinistramente evoluindo ao largo; pequenos ntumbwés com as suas asas pairando sobre as águas como as das borboletas, tímidos como elas; gasolinas ronceiros que chegam fumegando pelo atalho do mangal, se a maré cheia o permite, para que os passageiros, quem quer que sejam, se possam deslumbrar com a visão do Ibo emergindo da folhagem. Joia brilhante, ilusão. (COELHO, 2005, p. 198) 
Os barcos são cosmos em miniatura nesse espaço índico, reveladores do genius do lugar, da forma como vivem as sociedades costeiras e das ilhas em Moçambique, similares a outras zonas litorâneas do Oceano Índico.

A propósito do Oceano Índico, Michael Pearson (2003, p. 5) refere que "A history of an ocean needs to be amphibious, moving easily between land and sea". 9 E é isso que acontece com a segunda narrativa "A força do mar de Agosto", que ganha a dimensão de uma parábola, evocando intertextual e fragmentariamente as narrativas bíblicas da separação das águas, de Jonas engolido pela baleia, ou ainda o mito da caverna de Platão, com o desaparecimento das águas da baía de Maputo. O conto de JPBC começa assim: "Um dia acordou a baía sem água" (COELHO, 2005, p. 125).

\begin{abstract}
Até onde a vista alcançava - que no caso dos pescadores é bem longe, habituados que estão a perscrutar uma superfície que é lisa e sem obstáculos - ficara aquilo tudo um deserto. Um deserto salpicado de pequenos pontos prateados, brancos e negros ou até de outras cores, que eram os peixes contorcendo-se em busca de ar ou água, ou ar na água. (COELHO, 2005, p. 127)
\end{abstract}

É a partir da transformação do mar em terra que o narrador apresenta uma visão excêntrica do espaço índico, proporcionando simultaneamente uma reflexão sobre memória e passado colonial, e sobre o presente pós-colonial. Para o autor, o Índico é lugar de cruzamentos e de contradições, de trocas comerciais e culturais, mas também de memória da escravatura e da empresa colonial. Assim, compreende-se que a vastidão de terra descoberta, pelo esvaziamento do mar, seja reveladora de segredos trágicos, naufrágios, restos de corpos, de navios, de tempos sobrepostos, que se misturam num enorme cemitério e num extenso deserto, metáforas que acentuam a dimensão visionária e simultaneamente paródica da narrativa.

"A força do mar de Agosto", por meio das suas pequenas narrativas internas, que descobrem, passo a passo, a vastidão do cemitério/ deserto marítimo, chama a atenção para questões ecológicas, políticas e históricas. O mar transforma-se em nova terra e novo mapa a preencher, agora descoberto, a nu, demasiadamente visível. O que o mar engoliu, tal como a baleia a Jonas, desvenda-se, permitindo conhecimento e estupor. Indiciadora de histórias de várias épocas, a visão necrotéria daquele deserto húmido transforma-se agora em projeto de novas trocas comerciais, nova

9 "A história de um oceano precisa ser anfíbia, movendo-se com agilidade entre a terra e o mar." 
urbanização e ocupação. Ou seja, descoberto o bojo das narrativas ocultas do mar, transforma-se esse legado em moeda de troca de outras obscuras narrativas da terra.

Entretanto, no extremo de cima assustavam-se os da Ilha da Inhaca. É que desde sempre tinham visto o sol pondo-se numa minúscula cidade de Maputo ao longe, sempre envolta em névoa, o seu mistério amansado pela distância e pela repetição. E agora murmurava-se de boca em boca, ela aproximar-se-ia ruidosa num som rouco de bulldozers como um voraz bicho já arrotando antes de comê-los. Lançaria as suas avenidas como um grande polvo lançando os tentáculos, exalaria os seus fumos negros e espessos de cidade como esse polvo lança a sua tinta. Metáfora marinha, mas nem por isso menos ameaçadora e real. Ilhéus que eram, temiam essas coisas por não ter retaguarda para onde fugir. (COELHO, 2005, p. 137)

A parábola encena uma tentativa de desvendar os mistérios postos a descoberto pelo mar, agora terra, invertendo geografias, parodizando as novas trocas comerciais, os interesses económicos transnacionais, o desrespeito pela ecologia e pela natureza.

Para entender o fenómeno do desaparecimento do mar, foram chamados vários intervenientes. Primeiro veio a Brigada dos Técnicos, numa tentativa frustrada de entender o caso, munida de "réguas e compassos, teolitos e gepeésses, binóculos e telemóveis, lépetopes e transmissores com os respectivos repetidores" (COELHO, 2005, p. 130), tudo isso para encontrar a causa do desaparecimento repentino do mar. Na sequência narrativa há, depois, necessidade de recorrer à ajuda aérea dos sul-africanos que mapeiam fotograficamente toda a extensa área de destroços e naufrágios.

Depois, em novo quadrado, surpreendidos pelos flashes do sul-africano equipamento, mágica aparição, um grupo de marinheiros austríacos a soldo de um tal Guilherme Bolts, procurando ainda recolher a vela do estai para oferecer menos resistência à traiçoeira tempestade que se abateu sobre o barco sem aviso, num fim de tarde de Setembro de 1779, naqueles desconhecidos e longínquos mares africanos. (COELHO, 2005, p. 132)

Por fim, também os norte-americanos se ofereceram para cooperar, pois possuem uma forma diferente de fotografar aquele espaço, através de satélites. Após um lento e sucessivo desvendamento do mapa de vestígios amontoados no interior do mar, a narrativa encena os planos para a construção de uma nova cidade, arquitetada em espaços quadriculados a ocupar. Mas a narrativa termina dando lugar de novo à natureza, à normalidade, voltando o mar a encobrir a baía. 
Foi nesta altura do processo, quando subia o tom da altercação - os planeadores procurando satisfazer o apetite e o povo também, cada um o respectivo que aconteceu aquilo que só pode acontecer no mês de Agosto. O cacimbo, aquecido por um sol que se fortalecia à medida que subia a encosta do dia, começou a liquefazer-se e com isso se desfizeram os seus secretos jogos de espelhos e reflexos, mágicos e tortuosos caminhos da visão: afinal havia mar, só que tão quieto e transparente, tão leve e tão etéreo que passara despercebido!

(COELHO, 2005, p. 139)

JPBC configura nessa narrativa uma geografia criativa e imaginária que reverte mar em terra e transparência em obscuridade, criando pontes entre passado e presente, numa lógica movente da economia e transação, que une a profundidade do tempo (a caverna do mar, os múltiplos passados) à superfície transparente do presente. As narrativas de Índicos indícios circulam porosamente, repondo zonas de contacto, em que as estórias se entrelaçam e repetem de outras formas. Passado colonial e presente pós-colonial (re)negociam as narrativas.

Comércio crítico de fábulas, recriação de geografias e mitos, a narração de JPBC reinventa imaginários índicos, na procura do genius loci de um oceano, simultaneamente mágico, encantatório, trágico e soturno, em narrativas alternativas.

Can we develop our knowledge of an area like the Indian Ocean - producing and trading in facts - without references to the narratives that underpine that trade? These are colonial fictions. Can we be sure our knowledge is not compromised by that kind of fictional framework? And there are post-colonial fabulations, stories that describe other kind of becomings. (MUECKE, 2010, p. $72)^{10}$

\title{
NARRATIVES OF THE INDIAN OCEAN IN THE JPBC'S WORK - A TRANSNATIONAL GEOGRAPHY
}

\begin{abstract}
In this paper, we aim to discuss the importance of the narrative as a cultural element of transit that entwines the shores of the Indian Ocean, creating a geography of the space between the coastline and the islands. We further aim to demonstrate how that transit is charted in the writings of João Paulo Borges Coelho and how the author interweaves two different types of Indian Ocean topography representation: the descriptive meta-narrative of historical origin and
\end{abstract}

10 "Seremos capazes de desenvolver o nosso conhecimento de uma área como o Oceano Índico - que produz e negocia histórias - sem referências às narrativas que sustentam esse comércio? Essas são as ficções coloniais. Poderemos ter certeza de que o nosso conhecimento não é comprometido por esse tipo de quadro ficcional? E há ainda as efabulações pós-coloniais, histórias que descrevem outros tipos de relatos, de devir." 
the literary-fictional narrative, which lies at the intersection of myth and history. A fragmentary geography of the Indian Ocean, built in different narratives, is thus mapped onto this creative duplicity of the Mozambican author.

Keywords: Indian Ocean Studies; narrative; geography.

\section{REFERÊNCIAS}

BOSE, Sugata. A Hundred Horizons. The Indian Ocean in the Age of Global Empire. Cambridge/Massachusetts/Londres: Harvard University Press, 2006.

COELHO, João Paulo Borges. Índicos indícios: I Setentrião. Lisboa: Caminho, 2005a.

COELHO, João Paulo Borges. Índicos indícios: II Meridião. Lisboa: Caminho, 2005b.

COELHO, João Paulo Borges. O Índico como lugar. Colóquio Indicities/Indices/Indícios "A hibridação nas literaturas do oceano Índico". Universitat Autònoma de Barcelona, Barcelona, Espanha, 2009. (Mimeo)

GUPTA, Pamila; HOFMEYER, Isabel; PEARSON, Michael (Eds.). Eyes Across the Water Navigating the Indian Ocean. Pretoria: Unisa Press - University of South Africa, 2010.

GHOSH, Devleena; MUECKE, Stephen (Eds.). Cultures of Trade Indian Ocean Exchanges. Newcastle: Cambridge Scholars Publishing, 2007.

MOORTHY, Shanti; JAMAL, Ashraf (Eds.). Indian Ocean Studies Cultural, Social, and Political Perspective. Nova York/Londres: Routledge, 2010.

PEARSON, Michael. The Indian Ocean. Nova York/Londres: Routledge, 2003. 